\title{
Switching from an LHRH Antagonist to an LHRH Agonist: A Case Report of 10 Finnish Patients with Advanced Prostate Cancer
}

Harri Visapää

Received: December 14, 2016/ Published online: February 9, 2017

(C) The Author(s) 2017. This article is published with open access at Springerlink.com

\section{ABSTRACT}

Introduction: Luteinizing hormone-releasing hormone (LHRH) analogues are widely used for the treatment of advanced hormone-dependent prostate cancer. However, there are currently no clinical guidelines for switching between LHRH analogues. It has been reported that there may be clinical benefits for patients switching between different formulations of LHRH agonists, as well as from an LHRH agonist to LHRH antagonist, but there are no published data on switching from an LHRH antagonist to an LHRH agonist. In this paper, we summarize the clinical notes of 10 patients with hormone-sensitive advanced prostate cancer who switched from an LHRH antagonist to an LHRH agonist.

Methods: Patients with T3NOM0-T4N1M1 prostate cancer experiencing injection site reactions, such as pain and swelling, with monthly degarelix (Firmagon ${ }^{\circledR}$ ) subcutaneous

Enhanced content To view enhanced content for this article go to http://www.medengine.com/Redeem/ E787F0607539A79D.

H. Visapää $(\bowtie)$

Helsinki University Hospital Comprehensive Cancer

Center, Helsinki, Finland

e-mail: Harri.Visapaa@hus.fi injections were switched to the 3-monthly leuprorelin acetate implant (Leuprorelin Sandoz ${ }^{\circledR}$ ) subcutaneous injections.

Results: Mean patient age was 75 years (SD 8.3; range 59-85) and Gleason scores ranged from 7 to 9. The mean [ \pm standard deviation (SD)] duration of degarelix treatment was $5 \pm 3.7$ months (range 2-13). After switching, prostate serum antigen levels were comparable or reduced from those measured prior to switching, showing that efficacy was not compromised. Throughout the course of treatment, no patients reported injection site reactions. Patients reported increased satisfaction with the leuprorelin acetate implant versus degarelix, mainly because of a lack of injection site reactions and reduced frequency of injection.

Conclusion: This is the first report of the clinical experience and potential cost implications of switching from an LHRH antagonist to an LHRH agonist. These data are consistent with other experiences of switching between LHRH analogues in terms of efficacy, safety, and potential cost savings, and provide preliminary evidence that the switch from an LHRH antagonist to an agonist is safe and equally efficacious.

Keywords: Case report summary; Degarelix; Leuprorelin acetate; LHRH analogues; Prostate cancer; Switching 


\section{INTRODUCTION}

Androgen deprivation therapy (ADT) is still the mainstay of treatment for advanced hormone-dependent prostate cancer, with the main form being luteinizing hormone-releasing hormone (LHRH) agonists, such as goserelin acetate and leuprorelin acetate [1]. If permanent castration is required, orchiectomy is the most cost-effective and effective treatment option, but is very seldom used in clinical practice in Western countries.

Luteinizing hormone-releasing hormone (LHRH) agonists bind to the LHRH receptor and stimulate luteinizing hormone (LH) and follicle-stimulating hormone (FSH) secretion. Chronic exposure leads to downregulation of LHRH receptors, thereby suppressing LH and FSH secretion, and ultimately inhibiting testosterone production. Castration levels of testosterone with LHRH agonists are typically achieved within 2-4 weeks [2]. LHRH antagonists, such as degarelix, are an alternative form of ADT. They inhibit LHRH receptors, leading to a rapid decrease in $\mathrm{LH}$, $\mathrm{FSH}$, and testosterone levels, without the testosterone flare associated with LHRH agonists [2].

Clinical trials have compared the effects of LHRH agonists and LHRH antagonists on prostate-specific antigen (PSA) and testosterone levels, but large comparative trials are needed to provide overall survival and/or progression-free survival data [3]. Previous studies have also reported LHRH agonists and LHRH antagonists to be generally well tolerated (with most adverse events being consistent with androgen suppression or the underlying condition), with the exception of reactions at the injection site with LHRH antagonists [4-8].

Switching between hormonal therapies has been reported to have clinical benefits [6, 8-10]. There are currently no clinical guidelines for switching between LHRH analogues [2, 11, 12], but it has been reported that there could potentially be clinical benefits for patients if they switch between the different formulations of LHRH agonists [8] as well as from an LHRH agonist to LHRH antagonist $[6,10]$. There have, however, been no published data reported for switching from an LHRH antagonist to an LHRH agonist. Here we summarize the clinical notes of 10 patients with hormone-sensitive advanced prostate cancer who switched from an LHRH antagonist to an LHRH agonist.

\section{CASE PRESENTATION}

Ten patients with T3N0M0-T4N1M1 prostate cancer experiencing injection site reactions, such as pain and swelling, with monthly degarelix (Firmagon ${ }^{\circledR}$ ) subcutaneous injections were included within this collection of 10 case studies (Fig. 1). Mean patient age was 75 years [standard deviation (SD) 8.3; range 59-85] and Gleason scores ranged from 7 to 9 (Table 1). All patients provided informed consent and the study was carried out in accordance with ethical standards and Good Clinical Practice.

Primary treatment for prostate cancer was external beam radiation therapy $(n=9)$ or chemical castration $(n=1)$. The mean $( \pm \mathrm{SD})$ duration of degarelix treatment was $5 \pm 3.7$ months (range $2-13$ ). The first patient was switched to the leuprorelin acetate implant (Leuprorelin Sandoz ${ }^{\circledR}$ ), with no antiandrogen therapy, in December 2015 and the mean duration of treatment is currently 7 months (range 4-10). Of the 10 patients who switched from degarelix, three received the leuprorelin acetate implant before radiotherapy as neoadjuvant therapy and the seven men who received it as adjuvant therapy are still receiving the implant (Fig. 1). PSA levels were measured before and after switching treatments [time to post-switch PSA measurement, 1-6 months, mean $2.2 \pm 1.6$ (SD)]. PSA levels were comparable or reduced from those measured prior to switching, showing that efficacy was not compromised (Fig. 2). Mean PSA level before switching was $6.1 \pm 9.1$ versus $4.4 \pm 6.7 \mathrm{ng} / \mathrm{mL}$ after switching.

Throughout the course of treatment, no patients reported injection site reactions, such as pain or swelling, with the leuprorelin acetate implant. Patients reported increased satisfaction with the leuprorelin acetate implant than with 


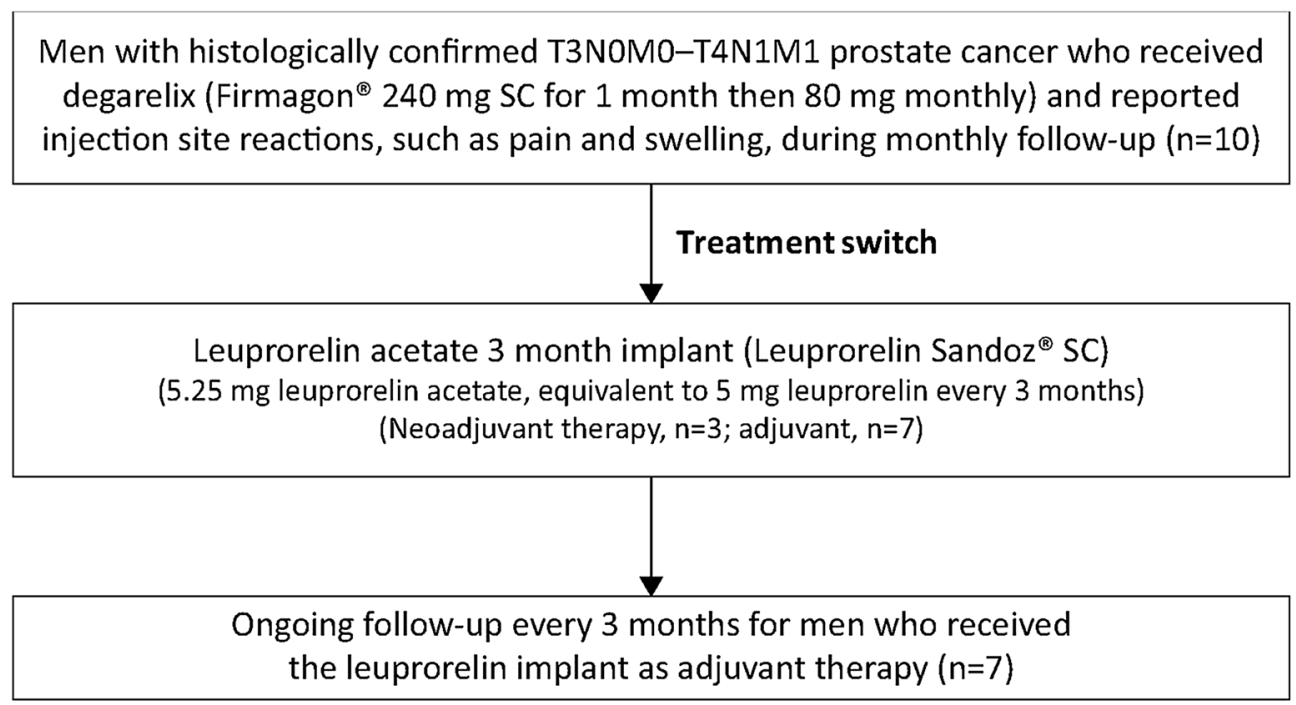

SC, subcutaneous

Fig. 1 Patient flow diagram

Table 1 Baseline characteristics and time to the first PSA test after switching to the leuprorelin acetate implant

\begin{tabular}{lllll}
\hline Patient & Gleason score & Gleason sum & cTNM & $\begin{array}{l}\text { Time to first PSA test } \\
\text { after the switch (months) }\end{array}$ \\
\hline 1 & $4+5$ & 9 & T3N0M0 & 2 \\
2 & $4+3$ & 7 & T3N0M0 & 1 \\
3 & $5+4$ & 9 & T4N1M1 & 4 \\
4 & $4+4$ & 8 & T3N0M0 & 2 \\
5 & $4+5$ & 9 & T3N0M0 & 6 \\
6 & $4+4$ & 8 & T3N0M0 & 2 \\
7 & $4+4$ & 8 & T3N0M0 & 2 \\
8 & $4+5$ & 9 & T3N0M0 & 1 \\
9 & $4+5$ & 9 & T3N1M1 & 1 \\
10 & $4+3$ & 7 & T3N1M1 & 1 \\
\hline
\end{tabular}

$P S A$ prostate-specific antigen

degarelix, mainly because of a lack of injection site reactions and reduced frequency of injection. Moreover, the 3-month injection interval with the leuprorelin acetate implant was reported by the patients to be preferable to the monthly interval of degarelix. Following the switch to the leuprorelin acetate implant in the adjuvant setting, all seven patients stated that they preferred to continue with this therapy.
In Finland, continuous treatment with the leuprorelin acetate implant also appeared to be more cost-effective due to reduced costs (decreased from $€ 517$ for 3 months treatment with degarelix to $€ 316$ for the leuprorelin acetate implant). In addition, costs associated with nurse involvement were reduced to one-third of the original cost due to less frequent administration of injections. 


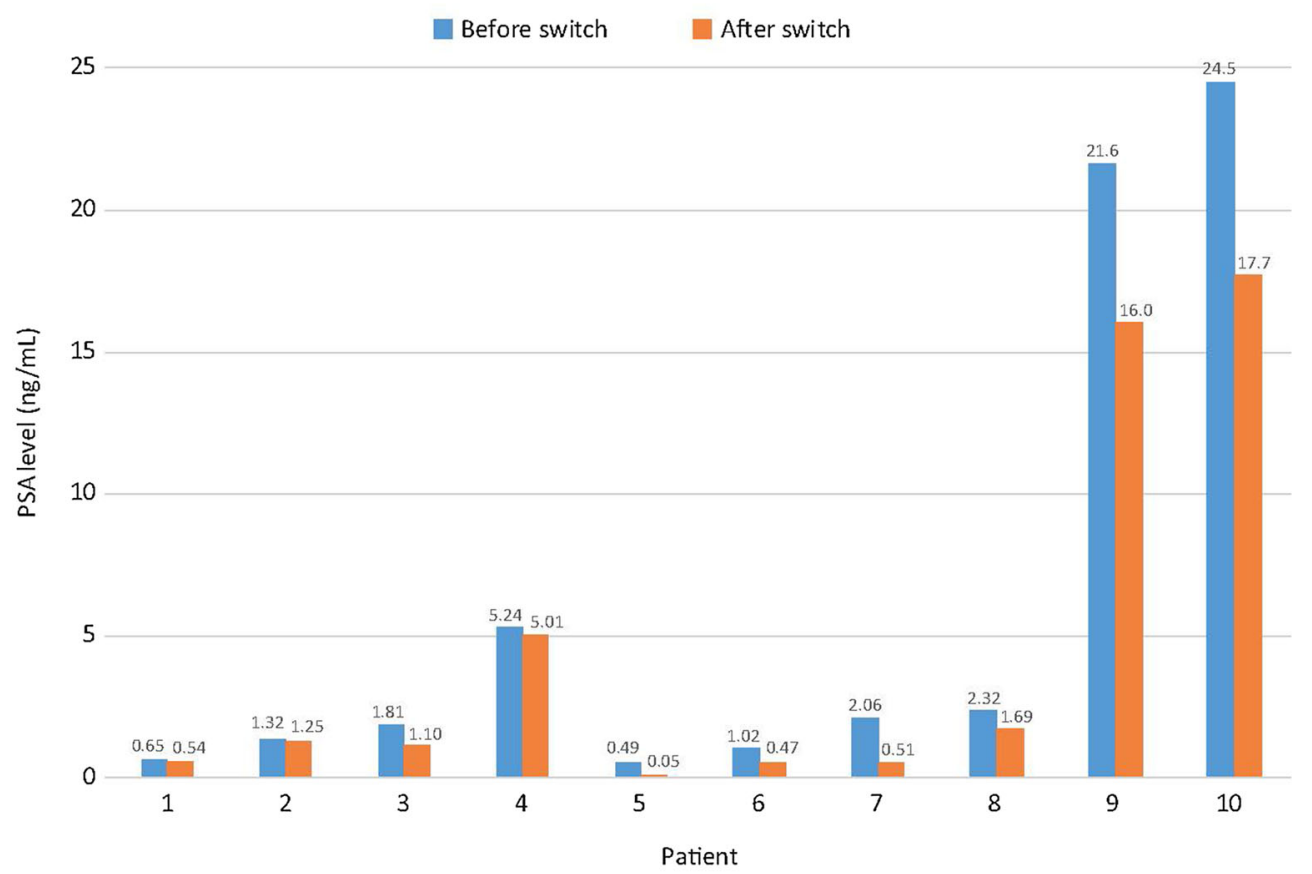

Fig. 2 PSA levels of 10 patients measured before and after switching from an LHRH antagonist to an LHRH agonist

\section{SUMMARY AND CONCLUSIONS}

This is the first report of the clinical experience and the potential for associated cost savings when switching men with advanced prostate cancer from an LHRH antagonist to an LHRH agonist. The recurrent injection site reactions experienced by all 10 Finnish patients who initially received degarelix could be attributed to the associated histamine release from mast cells, which has been associated with all LHRH antagonists [13]. The data reported here for men switching from degarelix to the leuprorelin acetate implant are consistent with other switching experiences between LHRH analogues in terms of efficacy and safety $[6,8,10]$ as well as the potential for associated for cost savings [1].

The case report presented here, therefore, provides preliminary evidence that the switch from an LHRH antagonist to an agonist is safe and equally efficacious. However, a prospective patient preference study reporting local adverse effects would be useful to support these findings, as well as a large comparative trial to compare overall survival and/or progression-free survival of LHRH agonists and LHRH antagonists [3].

\section{ACKNOWLEDGEMENTS}

No funding or sponsorship was received for the study. Article processing charges were funded by Sandoz International GmbH. The author collated the data in this study and takes complete responsibility for the integrity of the data and accuracy of the data analysis.

Medical writing support was provided by Sarah Stutfield, Spirit Medical Communications Ltd., supported by Sandoz International GmbH.

All named authors meet the International Committee of Medical Journal Editors (ICMJE) criteria for authorship for this manuscript, take responsibility for the integrity of the work as a whole, and have given final approval for the version to be published.

Disclosures. Harri Visapää has nothing to disclose. 
Compliance with Ethics Guidelines. All patients provided informed consent and the study was carried out in accordance with ethical standards and Good Clinical Practice.

Data Availability. The datasets during and/ or analyzed during the current study are available from the author on reasonable request.

Open Access. This article is distributed under the terms of the Creative Commons Attribution-NonCommercial 4.0 International License (http://creativecommons.org/licenses/ by-nc/4.0/), which permits any noncommercial use, distribution, and reproduction in any medium, provided you give appropriate credit to the original author(s) and the source, provide a link to the Creative Commons license, and indicate if changes were made.

\section{REFERENCES}

1. Merseberger A, Björk T, Whitehouse J, Meani D. Treatment costs for advanced prostate cancer using luteinizing hormone-releasing hormone agonists: a solid biodegradable leuprorelin implant versus other formulations. J Comp Eff Res. 2015;4:447-53.

2. Mottet N, Bellmunt J, Briers $\mathrm{E}$, et al. EAU-ESTRO-SIOG Guidelines on prostate cancer. http://uroweb.org/wp-content/uploads/EAUGuidelines-Prostate-Cancer-2016.pdf. Accessed 4 Nov 2016.

3. Salciccia S, Gentilucci A, Cattarino S, Sciarra A. GNRH-agonist or antagonist in the treatment of prostate cancer: a comparison based on oncological results. Urologia. 2016;83:173-8.

4. Klotz L, Boccon-Gibod L, Shore N, et al. The efficacy and safety of degarelix: a 12-month, comparative, randomized, open-label, parallel-group phase III study in patients with prostate cancer. BJU Int. 2008;102:1531-8.

5. Van Poppel H, Klotz L. Gonadotropin-releasing hormone: an update review of the antagonists versus agonists. Int J Urol. 2012;19:594-601.

6. Rick F, Block N, Schally A. An update on the use of degarelix in the treatment of advanced hormone-dependent prostate cancer. Onco Targets Ther. 2013;6:391-402.

7. Geiges G, Schrapperer E, Thyroff-Friedinger U. Clinical development of two innovative pharmaceutical forms of leuprorelin acetate. Ther Adv Urol. 2013;5:3-10.

8. Gravel P, Samland D, Löffler M, Maier S, Panozzo M, Muenzberg M. Two innovative pharmaceutical forms of leuprorelin: results from 818 patients with advanced prostate cancer. Adv Ther. 2013;30:271-85.

9. Kotwal S, Whelan P. Does failure of single hormone therapy delineate hormone refractoriness for prostate cancer? Scand J Urol Nephrol. 2008;42:116-20.

10. Crawford E, Tombal B, Miller K, et al. A phase III extension trial with a 1-arm crossover from leuprolide to degarelix: comparison of gonadotropin-releasing hormone agonist and antagonist effect on prostate cancer. J Urol. 2011;186:889-97.

11. Parker C, Gillessen S, Heidenreich A, Horwich A, ESMO Guidelines Committee. Cancer of the prostate: ESMO clinical practice guidelines for diagnosis, treatment and follow-up. Ann Oncol. 2015;26:v69-77.

12. National Comprehensive Cancer Network. NCCN Guidelines version 32016 [online]. http://www. nccn.org/professionals/physician_gls/pdf/prostate. pdf. Accessed 4 Nov 2016.

13. Klotz L. Degarelix acetate for the treatment of prostate cancer. Drugs Today (Barc). 2009;45:725-30. 